\title{
Quantitative microscopy reveals centromeric chromatin stability, size and cell cycle mechanisms to maintain centromere homeostasis
}

\author{
Ana Stankovic and Lars E.T. Jansen \\ Instituto Gulbenkian de Ciência, 2780-156 Oeiras, Portugal
}

\begin{abstract}
(115 words)
Centromeres are chromatin domains specified by nucleosomes containing the histone H3 variant, CENP-A. This unique centromeric structure is at the heart of a strong self-templating epigenetic mechanism that renders centromeres heritable. We review how specific quantitative microscopy approaches have contributed to the determination of the copy number, architecture, size and dynamics of centromeric chromatin and its associated centromere complex and kinetochore. These efforts revealed that the key to long-term centromere maintenance is the slow turnover of CENP-A nucleosomes, a critical size of the chromatin domain and its cell cycle coupled replication. These features come together to maintain homeostasis of a chromatin locus that directs its own epigenetic inheritance and facilitates the assembly of the mitotic kinetochore.
\end{abstract}

Main text: 7361 words

\section{CENP-A as the key epigenetic determinant of active centromeres}

Epigenetic traits are heritable features whose propagation is not solely driven by underlying DNA sequences. Centromeres are chromosomal loci whose propagation depend on such a mechanism. The current consensus in the centromere field is that the centromere-specific histone H3 variant CENP-A lies at the core of a positive epigenetic feedback loop and is sufficient to initiate and propagate centromeres. CENP-A, along with CENP-B and CENP-C were among the first centromere proteins to be identified using antibodies isolated from auto-immune sera from human scleroderma patients (CREST)(Earnshaw and Rothfield, 1985). These sera stained proteins at all active centromeres but, importantly, they are absent from an inactive centromere, suggesting a "chromatin based regulation" of the centromere (Earnshaw and Migeon, 1985). Soon after its initial discovery CENP-A was found to have histone-like properties and to copurify with core histone proteins (Palmer et al., 1987). Subsequent cloning of the gene, confirmed these properties (Sullivan et al., 1994). In 1993, the first human neocentromere was described (Voullaire et al., 1993), a functional centromere located on a deleted 
derivative of chromosome 10 in human patient samples, lacking typical centromeric sequence as well as the CENP-B protein that binds to those sequences. Indeed, CENP-B knockout mice are viable (Hudson et al., 1998), strengthening the notion that centromeric DNA is not the main driver of centromere positioning. In addition, centromere specific CENP-A homologues exist in nearly all species analyzed so far (Malik and Henikoff, 2003; Talbert et al., 2012), with the exception of kinetoplastids and some holocentric insects that do not appear to contain a recognizable CENP-A homologue (Akiyoshi and Gull, 2013; Drinnenberg et al., 2014). A remarkable feature of centromeric chromatin is its requirement for the maintenance of centromeric chromatin across the germline in several, but not all organisms analyzed thus far. In mammals, early work has shown that CENP-A is present in mature bovine sperm, evading protamine deposition (Palmer et al., 1990), suggesting CENP-A may play a transgenerational role in mammals. Indeed, stable paternal transmissions of neocentormeres within human families demonstrate that the position of the centromere is inherited epigenetically at least through the male germline (Amor et al., 2004; Tyler-Smith et al., 1999). Sperm retained CENP-A was also found in X.laevis and D. melanogaster (Dunleavy et al., 2012; Milks et al., 2009; Raychaudhuri et al., 2012). In Drosophila, a causative role for CENP-A in germline centromere maintenance has been shown. Selective removal of the CENP-A homologue [known as CID or cenH3 (Talbert and Henikoff, 2013)] from paternal centromeres resulted in successful fertilization but in the selective failure to segregate paternal chromosomes in the zygote, despite normal segregation of maternal chromosomes and the availability of a maternal pool of CID (Raychaudhuri et al., 2012). The transgenerational necessity of CENP-A is not universal in life. C. elegans, sperm is devoid of CENP-A which is provided de novo through the maternally deposited pool of CENP-A (Gassmann et al., 2012). Further, during oogenesis, pre-existing CENP-A is removed, and is de novo deposited (Monen et al., 2005).

In proliferating somatic cells, loss of CENP-A is lethal due to the severe defects in chromosome segregation in all species analyzed (Black et al., 2007a; Blower and Karpen, 2001; Buchwitz et al., 1999; Fachinetti et al., 2013; Henikoff et al., 2000; Howman et al., 2000; Régnier et al., 2005; Stoler et al., 1995; Talbert et al., 2002) Additionally, CENP-A is sufficient for the recruitment of virtually all known centromere and kinetochore proteins (Barnhart et al., 2011; Carroll et al., 2009; Foltz et al., 2006; Guse et al., 2011; Heun et al., 2006; Liu et al., 2006; Mendiburo et al., 2011; Okada et al., 2006), with the exception of the sequence specific DNA binding protein CENP-B (Pluta et al., 1992; Voullaire et al., 1993). In a groundbreaking study, (Mendiburo et al., 2011) used Drosophila S2 cells to tether CENP-A to a naïve chromatin domain containing Lac operator sequences (using a LacI DNA binding domain), not previously associated with centromere function. Once tethered, CENP-A AID-LacI creates a local nucleosomes pool that is able to recruit virtually all known downstream centromere and kinetochore proteins 
allowing stable binding of microtubules. Importantly, once formed, this nascent centromere recruited naïve CENP-A ${ }^{C I D}$, not previously associated with this region, even after the initial tether has been lost, indicative of self-propagation of CENP$\mathrm{A}^{\mathrm{CID}}$. Analogous experiments were performed with the CENP-A loading factor HJURP. In this case not only neocentromere formation was observed (Barnhart et al., 2011; Hori et al., 2013) but this centromere was shown to rescue chromosome stability and cell viability after deletion of the endogenous centromere in chicken DT40 cells (Hori et al., 2013). A large network of proteins, termed the constitutive centromere associated network (CCAN), is assembled on the centromere throughout the cell cycle (Cheeseman and Desai, 2008; Foltz et al., 2006; Izuta et al., 2006; Okada et al., 2006). Intriguingly, (Hori et al., 2013) found that tethering of the CCAN components CENP-C or CENP-I also initiates centromere formation, indicating that the broader centromere is actively participating in maintenance of a positive epigenetic feedback loop. These experiments provide compelling evidence that CENP-A is central to a positive feedback loop which supports stable inheritance of a centromere structure. A key question that follows is, if CENP-A is the heritable mark of the centromere, how is it itself inherited? Heritable systems, whether genetic or epigenetic, adhere to some basic principles that include (1) the ability to survive through key steps of the cell cycle such as DNA replication, transcription and mitosis, (2) have the capacity to drive template-directed duplication and (3), the duplication of the mark is regulated such that each molecule gives rise to an equal number of copies in synchrony with cell division (see also Gómez-Rodríguez and Jansen, 2013). In this chapter we discuss our current understanding of the heritable nature of centromeric chromatin which is the sum of its molecular stability, rates of replenishment and mechanisms that maintain these parameters in balance.

\section{CENP-A nucleosomes are stably propagated at centromeres through mitotic and meiotic divisions}

Early work indicates that total cellular CENP-A protein exhibits a remarkably long half-life and lives as long as the cell itself, equating $\sim 50 \%$ decrease per cell generation (Shelby et al., 1997). The apparent slow turnover required the employment of specific tools to assess protein dynamics. Fluorescence recovery after photobleaching (FRAP) which relies on local, irreversible photo-bleaching of a fluorophore, followed by subsequent repopulation of a bleached area with unbleached molecules provides information of the local rate of protein turnover. FRAP experiments on budding yeast kinetochores (containing a single microtubule attachment site), revealed that the yeast CENP-A homologue, Cse 4 displays very low turnover rates at centromeres except during $S$ phase where all of the preexisting Cse4 nucleosomes are exchanged (Pearson et al., 2004). Cse4 was found to be stable specifically at the centromere, whereas the non-centromeric Cse4 is degraded via ubiquitin-mediated proteolysis (Collins et al., 2004). Stable 
binding of Cse4 at centromeres was recently confirmed in elegant experiments using a photoconvertible Cse4-tdEos (Wisniewski et al., 2014). Eos, green in the unconverted state can be stably switch to red emission upon short wavelength excitation. Following conversion, Cse4 molecules were found to be stably associated with centromeres until their turnover during DNA replication.

Stability of the fission yeast, kinetochore-bound, CENP-A homologue was demonstrated using, once again, photobleaching of Cnp1-GFP (Coffman et al., 2011), which displayed a similar dynamics as previously described for Cse 4 (Pearson et al., 2004). Interestingly, in contrast to the yeasts, holocentric C. elegans embryos, characterized by extremely short division times ( $15 \mathrm{~min})$, photobleaching of embryonic CeCENP-A-GFP in anaphase in the one-cell embryo results in the complete fluorescence recovery in the next cell division, indicative of complete loss of pre-existing CeCENP-A nucleosomes (Gassmann et al., 2012). Here, sites for CeCENP-A deposition appear to be based on other genomic features rather than pre-existing CENP-A. These regions include those with low transcriptional activity in the parental germline (Gassmann et al., 2012) and sites of high DNA accessibility (Steiner and Henikoff, 2014).

In vertebrate cells, following the initial determination of CENP-A stability with a tagged shut-off allele in human cells (Shelby et al., 1997), a shut-off in the context of a full deletion of the CENP-A gene in chicken DT40 cells (Régnier et al., 2005) revealed that the loss rate of the cellular CENP-A pool is very slow indeed, with the first mitotic defects occurring only after 7-8 cell cycles. Similar results were obtained in human cells after conditional deletion of CENP-A (Fachinetti et al., 2013). The fact that these cells can survive for extended amount of time without continuous supply of fresh CENP-A, strongly suggests that pre-existing CENP-A, once assembled into nucleosomes, remains stably bound to centromeric chromatin. While these studies determined that CENP-A turns over slowly, establishing the actual turnover rate proved difficult to determine. The FRAP methodology is suitable for determining protein dynamics at short time scales such as in organisms which have a short cell division time, but proofs limited for dissecting protein turnover and replenishment rates at long time intervals. This limitation was surmounted by the use of a fluorescent pulse labeling strategy such as SNAP-tag technology, which allows for pulse labeling and visualization of different cohorts of the same protein within whole cell populations. SNAP is a derivative of a human DNA repair enzyme, $0^{6}$-alkylguanine-DNA alkyltransferase (AGT). The endogenous AGT enzyme recognizes $\mathrm{O}^{6}$-alkylated guanine in DNA, and transfers the alkyl group to a reactive cysteine residue. This self-labeling capacity is exploited in a mutant version of AGT (commonly known as SNAP) which has a high affinity towards synthetically engineered small, cell permeable molecules, such as benzylguanine (BG)(Keppler et al., 2003). The enzymatic reaction between SNAP and its substrate is irreversible, highly efficient and specific. Combining serial labeling of SNAP-tagged proteins with different SNAP substrates enables 
visualization and fate determination of pre-existing versus newly synthesized pools of the same protein (see Bodor et al., 2012 for extended review). Following a pulse labeled cohort of CENP-A-SNAP molecules over the course of 48-72 hours, demonstrated the stable transmission of CENP-A through mitotic divisions (Bodor et al., 2013; Jansen et al., 2007). The loss rate of this pool was found to equate $\sim 50 \%$ during each cell division, consistent with quantitative recycling of old CENPA during S phase, with no additional turnover (Bodor et al., 2013; Dunleavy et al., 2011; Jansen et al., 2007). This high rate of retention appears to be unique to CENP-A nucleosomes. Similar pulse labeling experiments on H3.1 and H3.3 did not reveal such retention at centromeric chromatin (Bodor et al., 2013; Falk et al., 2016), indicating that the property of stable transmission is linked to CENP-A itself, not the centromeric chromatin environment as a whole. However, histone H4 shows a striking differential stability. In the genome overall its turnover rates are similar to that of H3.1, but at the centromere $\mathrm{H} 4$ is retained to the extent of CENP-A (Bodor et al., 2013). CENP-A directly contacts H4 in the prenucleosomal complex as well as within the nucleosome, forming a highly rigid structure (Black et al., 2004, 2007b), likely directly stabilizing $\mathrm{H} 4$ at the centromere. The other remaining nucleosome partners, $\mathrm{H} 2 \mathrm{~A}$ and $\mathrm{H} 2 \mathrm{~B}$, like $\mathrm{H} 3.1$ and $\mathrm{H} 3.3$ do not display any elevated retention at the centromere (Bodor et al., 2013). Hence, CENP-A/H4 forms a stable subnucleosomal complex that represents the epigenetic core of the centromere which is quantitatively maintained throughout multiple cell divisions. The portion of CENP-A that confers its centromere targeting lies within its histone fold domain (HFD), in a subdomain termed CENP-A targeting domain (CATD), consisting of loop 1 and the $\alpha 2$-helix (Black et al., 2004). Replacement of the equivalent domain in $\mathrm{H} 3$ with that of CENP-A is sufficient to target an H3 СATD chimera to centromeres (Black et al., 2004, 2007a) and neocentromeres (Bassett et al., 2010). Importantly, the CATD confers increased conformational rigidity to (CENP-A/H4)2 tetramers as well as to CENP-A nucleosomes (Black et al., 2004, 2007b) and maintains the same loading dynamics as wild type CENP-A (Bodor et al., 2013). Remarkably, although not all CENP-A properties are reproduced after a genetic substitution by H3 ${ }^{\text {CATD }}$ (Fachinetti et al., 2013), this chimera retains the capacity to maintain its own centromeric levels over multiple cell cycles, suggesting that CATD is the critical subdomain responsible for longevity of the CENP-A nucleosome in vivo. Therefore, CATD emerges as a key molecular determinant discriminating CENP-A from histone $\mathrm{H} 3$, and implies that the extreme stability of CENP-A nucleosomes is encoded within CENP-A molecule itself. Recent work however defined CENP-C, a member of CCAN network, as an additional extrinsic factor contributing to CENP-A stability. CENP-C binds directly to chromatin-bound CENP-A, and as a consequence, induces structural changes in conformation of CENP-A nucleosomes. This result in increased rigidity of CENP-A nucleosomes, a feature likely contributing to its stable maintenance at centromeres, since CENP-C depletion causes a rapid loss of CENP-A from the chromatin (Falk et al., 2015). 
The most striking example showcasing extreme stability of CENP-A nucleosomes is recent work in female mouse meiosis (Smoak et al., 2016). Like in humans, mouse oocytes are arrested in meiotic prophase I for an extended period of time. CENP-A is readily detected in arrested mouse oocytes. However, no assembly occurs at any appreciable rate. Remarkably, deletion of the CENP-A in early oogenesis has no impact on long term ( $\sim 1 \mathrm{yr})$ retention of centromeric CENP-A despite the lack of a nascent pool.

\section{CENP-A copy number and the size of centromeric chromatin}

Due to its particularly strong epigenetic nature, centromeres represent an ideal model system for studying the basic principles of epigenetic inheritance. In the case of genetic inheritance, one DNA molecule will give a rise to two, and these will be inherited by two daughter cells. Likewise, a pre-S phase, parental centromere will give rise to two daughter centromeres, in a process that ultimately depends, not only on CENP-A but on a critical number of CENP-A molecules to maintain centromere identity.

\subsection{Budding yeast}

Initial biochemical characterization of centromeric chromatin was performed on the non-repetitive point centromere of budding yeast. In contrast to higher eukaryotes, whose centromeres associate with highly repetitive long DNA regions, S.cerevisiae centromeres assemble on a unique $\sim 125$ bp DNA sequence, allowing Chromatin Immunoprecipitation (ChIP) analysis of CENP-A bound domains. This approach found the budding yeast CENP-A homolog, Cse4 to be highly enriched at a single nucleosomes position and devoid from the adjacent sequences (Furuyama and Biggins, 2007), strongly indicating that budding yeast centromeres harbor a single stably bound Cse4 nucleosome. Since $S$. cerevisiae contains 16 clustered centromeres, bearing two Cse 4 molecules per nucleosome, yeast centromere foci have been extensively used as fluorescent standard representing 32 molecules.

Orthogonal methods to determine Cse4 copy number include fluorescence correlation spectroscopy (FCS) measurements of Cse4-EGFP (Shivaraju et al., 2012). FCS provides a measure of protein concentration in solution by determining fluctuations of fluorescence as molecules pass through a sub-femtoliter volume excited by a laser. FCS was used to calibrate cytosolic EGFP fluorescence and applied as standard to estimate the number of Cse4-EGFP molecules at the cluster of 16 centromeres. The results pointed at a single molecule of Cse4 per centromere, a surprisingly low number, which only transiently doubles in anaphase through mitotic exit. However, these changes in fluorescence could be confounded by the higher degree of centromeric chromatin compaction at this stage (Pearson et al., 2001; Wisniewski et al., 2014). Another attempt to count the 
absolute number of Cse4 (Aravamudhan et al., 2013) used stepwise photobleaching to find $\sim 1.7$ molecules at S. cerevisiae centromeres.

However, the single Cse4 nucleosome per centromere model was challenged by two contemporaneous studies that combined fluorescence measurements of Cse4GFP in living cells with established external fluorescent standards. Using E. coli EGFP-MotB ( $\sim 22$ molecules per focus) as a fluorescent standard (Coffman et al., 2011), authors reported 8 Cse 4 molecules per centromere. In a second study (Lawrimore et al., 2011) multiple fluorescent standards were employed, including single EGFP molecules, rotavirus-like particle-GFP-VLP2/6 (containing 120 EGFP molecules), a stably integrated 4-kb LacO array (containing 102 potential binding sites for LacI-GFP dimers) as well as the GFP-MotB protein from E.coli. By combining these standards, the authors obtained a mean number of 3,5-6 Cse4 molecules per centromere. Further, centromere dependency on a single nucleosome is also inconsistent with the observation that the amount of Cse 4 can be reduced by $\sim 40-60 \%$, without affecting kinetochore-microtubule attachments (Haase et al., 2013). It is possible that, in addition to a single stable positioned Cse4 nucleosome, extra copies are locally bound e.g. in a chaperone complex near the centromere that would be captured by microscopy-based methods.

The most recent study on this theme (Wisniewski et al., 2014), casts some doubt on previous studies, reporting extra-centromeric nuclear localization of Cse4 and impaired budding yeast growth when Cse4 is C-terminally GFP tagged. Normal cell growth can be obtained when Cse4 is internally tagged within its unstructured Nterminal tail. This study reported $\sim 2$ molecules of Cse4 per centromere based on ratiometric measurements against TetR-GFP bound to a tetO array. Nevertheless, it is not clear whether the tag interference affects all studies in a similar manner. Even though the precise CENP-A ${ }^{\text {Cse4 }}$ remains elusive (if there is indeed a fixed number), there is general consensus that few $(\leq 4)$ nucleosomes are present on budding yeast centromeres.

\subsection{Other yeasts}

The uncertainties of the Cse4 copy number propagated to attempts to count CENP$A$ at centromeres of other organisms. Based on Cse4, numbers were determined at centromeres of two other yeast species, C. albicans and fission yeast, S. pombe, (Joglekar et al., 2008). The authors reported $\sim 5$ molecules of CENP-A ${ }^{\text {Cnp1 }}$ at fission yeast centromeres and $\sim 8 \mathrm{CaCse} 4$ molecules in $C$. albicans. Taking into account the uncertainty in the budding yeast numbers, Candida features between 8 and 32 molecules of CENP-ACaCse4 per centromere. For fission yeast, the range would be 520 molecules per centromere. However, (Coffman et al., 2011) reported that the fission yeast strain used for these comparisons, is probably expressing a competing wildtype Cnp1 resulting in underestimation of Cnp1 numbers based on fluorescence. To readdress these confounded numbers, the authors used a clean 
genetic substitution of Cnp1 and the bacterial flagellar motor protein MotB, as fluorescent standard (Coffman et al., 2011; Leake et al., 2006), resulting in a much higher estimate of $226 \mathrm{Cnp} 1$ molecules per centromere. However, it is not clear how more than a hundred nucleosomes would fit a space of the $10 \mathrm{~kb}$ central core. Another, super-resolution-based method was used to count Cnp1 based on the photo-activatable protein, mEos2, which converts stochastically from a dark state to a fluorescent state once illuminated with low-intensity light (Lando et al., 2012). Subsequent bleaching ensures that each molecule is counted only once. Potential reactivation of fluorescence (blinking) can lead to double counting of molecules. After correction for blinking effects, $\sim 20$ molecules of Cnp1 per centromere cluster were reported. These numbers were corroborated using ChIP coupled to high throughput sequencing (ChIP-seq), identifying 20 distinct peaks of Cnp1 per centromere on average, placing an upper limit to the Cnp1 centromere occupancy ( $\sim 40$ nucleosomes per centromere). Taken together, it is clear that fission yeast centromeres are defined by a number of CENP-A nucleosomes that is an order of magnitude higher compared to budding yeast, clearly defining a regional centromere.

\subsection{Metazoans}

The first study carried out in metazoans aiming at establishing a centromeric CENP-A copy number used Drosophila imaginal disks carrying CENP-A ${ }^{\text {CID-EGFP as }}$ the sole source of CID and, once again, employing budding yeast Cse4-GFP as a standard for 32 fluorescent molecules (Schittenhelm et al., 2010). According to these measurements, 84-336 molecules of CENP-A CID are present per centromere, depending on the budding yeast numbers. Similar studies were performed in vertebrates, in chicken DT40 cells (Johnston et al., 2010; Ribeiro et al., 2010). The Johnston et al. study reported at least 62 molecules (using Cse4 as a fluorescent standard). Ribeiro et al., relied on counting of photoblinking events of a photoconvertible Dronpa CENP-A fusion arriving at 25 - 40 molecules of CENP-ADronpa. As stated by the authors, variation in photoblinking confound the results to some extent. Importantly, both studies were performed in the presence of endogenous CENP-A pools, restricting the results to lower estimates. In human cells, using a 3D imaging strategy combined with a clean genetic replacement of endogenous CENP-A in retinal pigment epithelium (RPE) cells reported $\sim 400$ molecules per centromere (Bodor et al., 2014). Centromere derived YFP-CENP-A signals (the only source of CENP-A in the cell) were measured and compared with total cellular levels. Remarkably, this analysis showed that while CENP-A is enriched at the centromere, on average only $0.44 \%$ of cellular CENP-A resides at each centromere. Interestingly, this ratio appeared to be fixed between RPE cell lines expressing variable levels of CENP-A, suggesting this ratio is likely preserved in unmodified, wild type RPE cells. The total cellular pool of CENP-A in wild type RPEs was found to be $\sim 91,000$ molecules (as determined by quantitative Western blotting using highly purified CENPA/H4 as a reference), which translates into 
400 molecules of CENP-A per centromere. The results were corroborated by employing the yeast the LacO/LacI-GFP standard (Lawrimore et al., 2011) as well as a statistical method based on the random segregation of CENP-A during DNA replication. Given, the predominantly octameric nature of CENP-A nucleosomes (Black and Cleveland, 2011; Hasson et al., 2013), this number converts into $\sim 200$ CENP-A nucleosomes in interphase, which are split into 100 nucleosomes on mitotic centromeres (Figure 1A). Surprisingly, this number is not uniform across different cell types which can be as low as 50 nucleosomes, still retaining the capacity to form a functional and heritable centromere (Bodor et al., 2014).

The scarcity of CENP-A nucleosomes at the centromere [1 in 25 compared to H3 on average (Bodor et al., 2014) appears to be inconsistent with the stable maintenance of a self-templating positive feedback loop, which typically relies on local cooperativity (Dodd et al., 2007). However, analysis of nucleosome distribution at neocentromeres, where such analysis is possible, shows that CENPA nucleosomes tend to be organized in clusters, as also found by chromatin fiber analysis (Blower et al., 2002). Within these clusters, individual positions harbor CENP-A with a remarkably high occupancy [up to $80 \%$ of total cells (Bodor et al., 2014)], indicative of a strong nucleosome positioning favoring CENP-A. Therefore, strong enrichment of CENP-A nucleosomes coupled with their possible clustering at the centromere likely provides an ample amount of CENP-A nucleosomes sufficient to maintain a positive epigenetic feedback loop (Figure 1B).

\section{The modularity of CENP-A dependent kinetochore assembly}

CENP-A acts as the most upstream component in kinetochore assembly by specifying the point of contact between the DNA and mitotic spindle. CENP-A directs the formation of the constitutive centromere associated network (CCAN) which in turn, during mitosis, recruits a secondary protein complex known as the kinetochore. The kinetochore includes the conserved microtubule-binding KMN network, consisting of the protein KNL1, the Mis12 and Ndc80 complexes (Cheeseman et al., 2004, 2006; DeLuca et al., 2006). Kinetochores serve as a platform for binding of dynamic spindle microtubules which exert poleward pulling forces onto centromeres and separate sister chromatids in opposite direction during anaphase.

Current models for centromere and kinetochore architecture are based on repeated individual subunits, in which the amount of centromere components directly dictates the number of downstream kinetochore proteins, and ultimately the number of microtubule attachment sites. This form of organization was initially proposed in 1991, when islets of proteins recognized via CREST antibodies were identified in a stretched centromeric DNA fiber (Zinkowski et al., 1991). Evidence for such a modular organization is found at the $S$. cerevisiae point centromere. Joglekar et al used endogenous GFP-tagging of the C-termini of kinetochore 
proteins and compared copy numbers to centromeric Cse4-GFP as a fluorescent standard assuming a single Cse 4 nucleosome (Joglekar et al., 2006). They found the proteins forming the interface between centromeric chromatin and the microtubule plus end to be present in specific stoichiometries. For example, 1-2 copies of Mif2p, the yeast CENP-C homolog, 2 - 3 copies of the COMA complex (containing several CCAN members), 6-7 copies of Mtw1p, the Mis12 homolog and 8 copies of the Ndc80 complex. However, it should be noted that the precise number of kinetochore units could be potentially higher, depending on the actual number of Cse 4 molecules at budding yeast centromeres.

Regional centromeres tend to assemble on large stretches of centromeric DNA compared to the budding yeast point centromeres and they are bound by multiple spindle microtubules [ranging from 2-4 in fission yeast to 17 in the case of humans (McEwen et al., 2001; Sagolla et al., 2003)]. Initial studies, focused on the centromeres of fission yeast and C. albicans (Joglekar et al., 2008), found a strikingly constant ratio between the amount of centromeric CENP-A nucleosomes, structural components of kinetochore and number of microtubules attached during mitosis. Based on mitotic fluorescent intensities of a multitude of kinetochore components [in a manner analogous to (Joglekar et al., 2006)], the authors revealed that, while absolute numbers differ, the number of kinetochore proteins per microtubule attachment are very similar between budding and fission yeast. For both yeasts there are 6-8 molecules of KMN network per kinetochoremicrotubule attachment. These findings strongly argue that the regional centromeres of fission yeast are composed of repeated structures reminiscent of the ones existing in budding yeast. This apparent kinetochore architecture extends to certain metazoan species, such are chicken DT40 cells, in which the copy number of CCAN network members (namely CENP-C, CENP-H, CENP-I and CENP$\mathrm{T}$ ) is in nearly stoichiometric relation to KMN network members (Mis12, Knl1 and Ndc80), which, once again assemble at $\sim 8$ molecules per microtubule (Johnston et al., 2010). However, a direct relationship between the number of centromeric CENP-A nucleosomes and amount of downstream kinetochore components is incompatible with the fact that constitutive overexpression of Cnp1 does not lead to significant changes in the copy number of kinetochore protein (Joglekar et al., 2008). Consistently, in C. albicans, the number of CaCse 4 nucleosomes is larger than the number of microtubule attachment sites (Joglekar et al., 2008), indicating that the relationship between centromeric chromatin and microtubule attachment sites is less defined. This notion is further supported by the fact that CENP-A depletion in human cells resulting in $\sim 7 \%$ of total centromeric (Fachinetti et al., 2013 ) or $\sim 10 \%$ of cellular pool (Liu et al., 2006) had no effect on centromere integrity at least in the short term. Upon partial loss of CENP-A, proteins such as CENP-C and CENP-T remain largely unaffected (Fachinetti et al., 2013). In an extreme case, upon complete acute complete loss of CENP-A, the centromere remains mitotically functional at least initially, after which failure to propagate the 
centromere in the next division results in gradual loss of centromere components (Hoffmann et al., 2016). In agreement with the stoichiometric disconnect between centromeric chromatin and the rest of the centromere, altering CENP-A levels in human RPE cell line between $40 \%$ and $240 \%$ relative to wild type, showed no significant effect on the amount of critical kinetochore proteins (Bodor et al., 2014). These included CENP-C and CENP-T, which are responsible for mitotic recruitment of the KMN network (Gascoigne et al., 2011), as well as the key microtubule binding protein Hec1/NDC80 (Cheeseman et al., 2006; DeLuca et al., 2006). Taken together, these results argue that on a typical human centromere the amount of CENP-A nucleosomes is in excess compared to the critical number necessary to maintain the centromere, which could in part be facilitated through semi-stable self-regulated recruitment of downstream CCAN proteins.

Another insight into the relationship between CENP-A chromatin and the kinetochore comes from overexpression studies. Excess CENP-A results in its mislocalization to non-centromeric sites (Athwal et al., 2015; Heun et al., 2006; Lacoste et al., 2014). Mistargeted CENP-A is not randomly distributed, rather it is enriched at sites of high histone turnover (Athwal et al., 2015; Lacoste et al., 2014). Even at physiological expression levels, CENP-A is present outside the centromere in a surprisingly high amounts. Quantitative fluorescence microscopy methods have estimated that only $\sim 20 \%$ of CENP-A is centromeric and about half of all CENP-A is chromatin bound elsewhere. However, due to the large genome size these CENP-A nucleosomes represent less than one in a thousand nucleosomes, compared to $\sim 50$ fold higher enrichment at centromeres (Bodor et al., 2014). Nonetheless, despite their presence in non-centromeric genomic locations, these CENP-A containing nucleosomes do not instigate the formation of the functional centromere (Bodor et al., 2014; Lacoste et al., 2014). It is tempting to speculate that whereas these sporadic genomic CENP-A nucleosomes might have limited capacity to attract some centromeric components, particularly those that directly interact with CENP-A (Gascoigne et al., 2011), the local pool of CENP-A does not reach a critical threshold sufficient to initiate the formation of a functional centromere. Therefore, rather than maintaining a linear relationship between CENP-A nucleosomes and downstream components, the CCAN and the kinetochore, once formed, maintain an internal stoichiometry and become to some extend independent of fluctuation in the centromeric CENP-A pool size.

One curious case in which the levels of centromeric CENP-A appear to dictate the amount of downstream kinetochore proteins has been reported to occur during meiosis in mice (Chmátal et al., 2014). In mammals, during female oogenesis only one out of four meiotic product will give rise to the future gamete. The probability for any allele to be transmitted should, in principle, follow Mendelian rules of inheritance. However, certain "selfish" genomic elements can skew this ratio and are preferentially retained in the mature egg, a process known as meiotic drive. The Chmátal et al. study showed that the amount of kinetochore proteins 
assembled at the meiotic centromere correlates with the amount of CENP-A nucleosomes. Chromosomes having fewer CENP-A nucleosomes at the centromere relative to the other ones, assembled a lower amount of Hec1/NDC80, which results in its positioning near the cell cortex due to asymmetric microtubule forces within the meiotic spindle resulting in its preferential exclusion to the polar body. The inverse was found for chromosomes with a higher amount of centromeric CENP-A nucleosomes, which were preferentially retained in the mature egg. While the resulting drive is not large, only by $10 \%$ form random (Chmátal et al., 2014), at evolutionary time-scales, this would have a profound effect on the frequency of a specific chromosome within a population. While in mitosis such inequalities maybe equalized by the mitotic checkpoint, this is much weaker during meiosis allowing for centromere discrepancies to evolve.

\section{Propagation of centromeric chromatin across cell divisions}

As outlined above, CENP-A nucleosomes are stably maintained and propagated at mitotic and meiotic centromeres (Bodor et al., 2013; Jansen et al., 2007; Smoak et al., 2016). This unusually slow turnover of CENP-A at each centromere (Falk et al., 2015) has consequences for how the correct levels are maintained across subsequent cell division cycles. New CENP-A histones can either be incorporated at a continuous slow rate to compensate for the two fold reduction during $\mathrm{S}$ phase, or alternatively, assembly is restricted to a discrete cell cycle window to control the rate and quantity of assembly. It turns out that, in all species examined thus far, control of CENP-A assembly is maintained by rendering it tightly cell cycle restricted rather than allowing continuous slow assembly. Given the key role of centromeres in mitosis and the fact that CENP-A is lost by two-fold during the preceding $S$ phase, it was initially expected that the replenishment of the $S$ phase diluted pool of CENP-A would occur prior to mitosis (Csink and Henikoff, 1998; Shelby et al., 2000). In budding yeast, as outlined above, CENP-A turns over during S phase (Pearson et al., 2004; Wisniewski et al., 2014). Such turnover appears to be a common feature among unicellular eukaryotes. In an interesting case of the unicellular red algae Cyanidioschyzon merolae, CENP-ACENH3 is detected at the centromeres only between $S$ phase and mitosis, and remains undetectable in G1

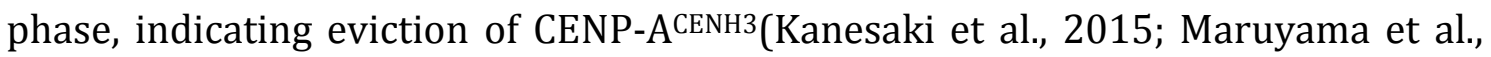
2007). Upon re-entry into subsequent $S$ phase, CENP-A $A^{\text {CENH3 }}$ is de-novo deposited at regional centromeres of $C$. merolae (Kanesaki et al., 2015). With the exception of these single celled organisms, CENP-A assembly appears to be uncoupled from DNA replication in metazoans and plants.

In most animal systems examined, a unique pattern of cell cycle-coupled CENP-A replenishment was uncovered where assembly of newly synthesized CENP-A is delayed until mitotic exit, in G1 phase of the next cell cycle, after the primary function of the centromere has been fulfilled. This paradoxical timing of centromeric chromatin assembly was initially discovered in Drosophila and human 
cells based on steady state fluorescence, FRAP experiments and SNAP-based pulse labelling, respectively (Jansen et al., 2007; Schuh et al., 2007). The SNAP technology has proven extremely useful in dissecting chromatin dynamics (Bergmann et al., 2011; Bodor et al., 2013; Deaton et al., 2016; Dunleavy et al., 2011; Jansen et al., 2007; Prendergast et al., 2011; Ray-Gallet et al., 2011). To assay for the assembly of nascent CENP-A-SNAP specifically, the pre-existing (chromatin bound) pool of CENP-A-SNAP is labelled with a non-fluorescent SNAP substrate (quench). During the ensuing chase period new, unlabeled CENP-A is synthesized which can be fluorescently labeled at a later time point (Bodor et al., 2012). This methodology allows for the visualization of centromeres decorated with nascent CENP-A. G1 restricted assembly of CENP-A in human cells was confirmed by photobleaching experiments of CENP-A-GFP (Hemmerich et al., 2008), and later also found be the conserved in chicken DT40 cells (Silva et al., 2012), and Xenopus (Bernad et al., 2011; Westhorpe et al., 2015). A key question that follows is to determine how CENP-A assembly is coupled to the cell cycle to maintain correct centromere levels. Early work showed that microtubule attachment and checkpoint signaling, two key aspects of mitosis, are not required for subsequent assembly (Jansen et al., 2007; Schuh et al., 2007). Instead, mitotic passage is primarily needed to result in APC-mediated cyclin destruction and concomitant loss of Cdk activity. This notion resulted from experiments demonstrating that selective inhibition of both Cdk1 and Cdk2 (Cdk1/2) in S or G2 phase is sufficient to induce premature, premitotic CENP-A assembly (Silva et al., 2012). CENP-A assembly commences rapidly upon Cdk inactivation, either naturally or artificially. This has led to a model in which all factors necessary for CENP-A loading are present and poised for activity prior to mitotic exit, but are held inactive due to the Cdk1/2 activities in S, G2 and mitosis, when these kinases are active. While CENP$A$ is the prime candidate regulating propagation of centromeric chromatin, the fact that $\mathrm{H} 3^{\mathrm{CATD}}$ chimera still retained $\mathrm{G} 1$ restricted timing of loading to the centromeres argues that external binding factors are likely contributors to cell cycle dependent CENP-A assembly, compared to CENP-A itself (Bodor et al., 2013). Indeed, the CENP-A specific chaperone HJURP is exclusively targeted to G1 centromeres (Dunleavy et al., 2009; Foltz et al., 2009), concurrent with its dephosphorylation on Cdk consensus residues (Müller et al., 2014; Stankovic et al., 2017). Mutation of Cdk responsive residues within HJURP prior to mitotic exit is sufficient to induce limited precocious loading of CENP-A at S and G2 centromeres (Müller et al., 2014; Stankovic et al., 2017). In addition, ectopic targeting of HJURP to centromeres prior to mitotic exit also leads to premature incorporation of CENP-A molecules, suggesting that rather than controlling the interaction interface between CENP-A and HJURP, the negative regulation occurs primarily at the level of localization of the assembly factor (Stankovic et al., 2017). Similarly, Cdk1/2 activities also negatively regulate centromeric localization of another CENP-A assembly factor, the M18 complex. This complex is targeted to centromeres in anaphase of mitosis, prior to the onset of CENP-A deposition, and its activity is 
necessary for subsequent steps in CENP-A deposition which involves the targeting of HJURP to the centromeres (Barnhart et al., 2011; Fujita et al., 2007). The largest member of the M18 complex, M18BP1 is under Cdk1/2 control, which limits its centromeric recruitment until loss of Cdk1 activity in anaphase (McKinley and Cheeseman, 2014; Silva et al., 2012; Stankovic et al., 2017). Interestingly, like HJURP, forced premature recruitment of M18BP1 to the centromeres can overcome negative cell cycle regulation to some extent (McKinley and Cheeseman, 2014; Stankovic et al., 2017). A single phosphorylation site at Threonine 653 is key to this control (Stankovic et al., 2017). This latter study showed that simultaneous expression of unphosphorylatable mutant forms of M18BP1 and HJURP, leads to their premature centromere targeting, resulting in essentially complete reconstitution of CENP-A assembly.

The requirement and sufficiency of these two targets defines a two-step inhibitory mechanism in which $\mathrm{Cdk} 1 / 2$ are directly targeting both assembly factors. This dual level control ultimately allows for a strict cell cycle coupled timing of CENP-A assembly (Figure 2). Recently, another kinase, Plk1, was shown to act as a positive regulator of CENP-A deposition. Its localization to G1 centromeres and contemporaneous phosphorylation of M18BP1 proved to be important for robust recruitment of the M18 complex to G1 centromeres. Interestingly, Plk1 activity is necessary for both canonical and premature (G2 phase) deposition of CENP-A, indicating the requirement of positive phospho-signaling at all cell cycle stages. Therefore, the strict cell cycle coupling of CENP-A loading is achieved through negative $\mathrm{Cdk} 1$ and 2-dependant signals, restricting assembly to G1 while positive signals, such as Plk1 are needed to stimulate assembly (Figure 2).

While CENP-A assembly is uncoupled from DNA replication in most eukaryotes, in fission yeast and plants, CENP-A assembly occurs in premitotic G2 phase (Lando et al., 2012; Lermontova et al., 2006), although the molecular details remain elusive. Another outstanding question is assembly control in Drosophila. While G1 phase is the major cell cycle window where CENP-A assembly occurs (Lidsky et al., 2013; Schuh et al., 2007), in Drosophila somatic cell lines, some degree of assembly also takes place in other phases, notably in mitosis (Lidsky et al., 2013; Mellone et al., 2011). However, in neuroblasts, within the in vivo context of the organism, CENP-A assembly remains G1-restricted (Dunleavy et al., 2012). Rather than indicting a fundamentally different logic of control, these differences likely reflect physiological differences in the efficiency of inhibition by the cell cycle machinery, as artificially achieved in human cells.

In sum, a picture emerges where different mechanisms have evolved all of which tie the CENP-A assembly machinery to the cell cycle. However, the importance of this for the maintenance of centromere structure and function remains largely undefined. 


\section{Possible mechanisms to maintain homeostasis of CENP-A levels across cell divisions}

The presence of pre-existing, chromatin bound CENP-A nucleosomes is a prerequisite for the stable propagation of centromeric domain. Parental CENP-A nucleosomes direct the incorporation of a nascent CENP-A molecules, which are placed adjacent to the pre-existing ones (Ross et al., 2016). This precise positioning of CENP-A molecules is likely facilitated through interaction between the constitutive centromeric protein CENP-C, which on one hand recognizes chromatin bound CENP-A (Carroll et al., 2010; Kato et al., 2013), and on the other, forms an interaction platform between the M18 licensing complex and centromeric chromatin (Dambacher et al., 2012; Moree et al., 2011; Shono et al., 2015; Westhorpe et al., 2015). This complex in turn recruits the CENP-A specific chaperone HJURP, (Nardi et al., 2016; Stellfox et al., 2016; Wang et al., 2014) which deposits newly synthetized CENP-A (Barnhart et al., 2011; Dunleavy et al., 2009; Foltz et al., 2009). These molecular connections likely contribute to a closed positive epigenetic feedback loop where deposition of new CENP-A is ultimately dependent on the previously incorporated pool. However, how the correct CENP-A levels are maintained remains an open question. Too little would render centromeres dysfunctional [e.g. reducing CENP-A levels to $10 \%$ is ultimately incompatible with viability of cells (Black et al., 2007a)], while too much CENP-A can potentially lead to neocentromere formation as is the case in Drosophila (Heun et al., 2006; Olszak et al., 2011).

The amount of CENP-A present at the centromeres is in a direct proportion to varying total cellular levels (Bodor et al., 2014) suggesting that the CENP-A loading machinery is not a rate-limiting factor controlling the size of centromeric domain, rather, it is CENP-A itself. The challenge to our understanding of how CENP-A levels are maintained is the fact that the chromatin bound pool does not exchange, rendering it invisible to a classic equilibrium. There is no apparent communication between soluble and centromeric CENP-A. This indicates that cells need some other measure of how much CENP-A is in chromatin and to adjust the assembly accordingly. Given the nature of a positive feedback loop, in the absence of a dynamic equilibrium, individual centromeres would have the potential of reaching extreme values, spinning out of control unless there is a mechanisms to curb the assembly of new CENP-A. In addition, due to the nature of chromatin recycling during DNA replication, CENP-A levels would be increasingly variable. Current evidence indicates that existing centromeric CENP-A is redistributed stochastically during DNA replication. The ratio in pool size between two sister centromeres follows a normal distribution averaging at 50/50 with a certain probability that one daughter centromere inherits a disproportionally larger (or smaller) number of parental CENP-A nucleosomes (Bodor et al., 2014). It is conceivable that there are surveillance mechanisms which would monitor and sense imbalanced number of CENP-A nucleosomes at each centromere. One possibility is that the CENP-A 
assembly machinery would incorporate a pool of molecules not in a direct relation to the number present in chromatin but load in excess, which has been observed (Jansen et al., 2007; Lagana et al., 2010). In this scenario, the correct amount would be determined in a later "maturation" step, in which the overloaded pool of new CENP-A would be removed from the centromere having an excess of parental CENP-A, whereas those with reduced levels would be stripped to a lesser extent (Figure 3). Should there be such an eviction mechanism, it would have to allow discrimination between CENP-A marked for instability versus the one which is destined to be stably inherited over cell cycle. Whereas molecular steps allowing eviction of overloaded pool of CENP-A are largely unknown, there are reports of stabilization of nascent CENP-A occurring in G1 (Lagana et al., 2010; Liu and Mao, 2016; Perpelescu et al., 2009), suggesting that addition of CENP-A "stabilization" mark would happen prior to DNA synthesis. A recent addition to this theme is the report of ubiquitylation of parental CENP-A as a requirement to recruit nascent CENP-A (Niikura et al., 2016). Centromeric CENP-A levels could also be normalized during $S$ phase passage, in which the mix of parental and G1-loaded pools of CENP-A would be coordinately and preferentially segregated to the granddaughter centromere which inherited a decreased number of CENP-A molecules from the previous generation. An elegant model has been proposed linking the amount of CENP-A assembly in G1 phase directly to the strength of the centromere in mitosis (Brown and $\mathrm{Xu}, 2009$ ). In this model, weaker centromeres would bind a smaller number of microtubules that would in turn generate a signal driving the assembly of a compensatory number of CENP-A molecules in the subsequent G1 phase (Figure 1C). One drawback of this model is that it assumes a proportional nature of kinetochore assembly in relation to the number of CENP-A molecules. However, variations of this model could be extended to modular kinetochores (assembled in a fixed rate independently of the number of CENP-A nucleosomes). Assuming nearly-equal numbers of microtubules attached to each daughter centromere (due to checkpoint signaling), the signal required to stabilize the amount of CENP-A molecules would come from the tension generated within centromeric chromatin. A speculative idea is that only those CENP-A molecules that are under tension are marked for stability whereas superfluous ones are marked for removal. In this way, over multiple mitotic divisions the number of CENP-A molecules would equalize. Individually or in combination, these mechanisms would have to rely on the presence of a yet to be identified rate limiting factors or a combination of factors that constitute a more stable measure of centromere size. These would need to have a capacity to recognize chromatinbound pool of CENP-A and contain "counting" properties allowing sensing of the size of CENP-A populated domain. CENP-C, a factor stabilizing CENP-A (Falk et al., 2015) could be one of such factors, limiting CENP-A domain size. 


\section{References}

Akiyoshi, B., and Gull, K. (2013). Evolutionary cell biology of chromosome segregation: insights from trypanosomes. Open Biol. 3, 130023.

Amor, D.J., Bentley, K., Ryan, J., Perry, J., Wong, L., Slater, H., and Choo, K.H.A. (2004). Human centromere repositioning "in progress." Proc. Natl. Acad. Sci. U. S. A. 101, 6542-6547.

Aravamudhan, P., Felzer-Kim, I., and Joglekar, A.P. (2013). The Budding Yeast Point Centromere Associates with Two Cse4 Molecules during Mitosis. Curr. Biol. 23, 770-774.

Athwal, R.K., Walkiewicz, M.P., Baek, S., Fu, S., Bui, M., Camps, J., Ried, T., Sung, M.-H., and Dalal, Y. (2015). CENP-A nucleosomes localize to transcription factor hotspots and subtelomeric sites in human cancer cells. Epigenetics Chromatin 8, 2.

Barnhart, M.C., Kuich, P.H.J.L., Stellfox, M.E., Ward, J.A., Bassett, E.A., Black, B.E., and Foltz, D.R. (2011). HJURP is a CENP-A chromatin assembly factor sufficient to form a functional de novo kinetochore. J. Cell Biol. 194, 229-243.

Bassett, E.A., Wood, S., Salimian, K.J., Ajith, S., Foltz, D.R., and Black, B.E. (2010). Epigenetic centromere specification directs aurora B accumulation but is insufficient to efficiently correct mitotic errors. J. Cell Biol. 190, 177-185.

Bergmann, J.H., Rodríguez, M.G., Martins, N.M.C., Kimura, H., Kelly, D.A., Masumoto, H., Larionov, V., Jansen, L.E.T., and Earnshaw, W.C. (2011). Epigenetic engineering shows H3K4me2 is required for HJURP targeting and CENP-A assembly on a synthetic human kinetochore. EMBO J. 30, 328-340.

Bernad, R., Sánchez, P., Rivera, T., Rodríguez-Corsino, M., Boyarchuk, E., Vassias, I., Ray-Gallet, D., Arnaoutov, A., Dasso, M., Almouzni, G., et al. (2011). Xenopus HJURP and condensin II are required for CENP-A assembly. J. Cell Biol. 192, 569-582.

Black, B.E., and Cleveland, D.W. (2011). Epigenetic Centromere Propagation and the Nature of CENP-A Nucleosomes. Cell 144, 471-479.

Black, B.E., Foltz, D.R., Chakravarthy, S., Luger, K., Woods, V.L., and Cleveland, D.W. (2004). Structural determinants for generating centromeric chromatin. Nature 430, 578-582.

Black, B.E., Jansen, L.E.T., Maddox, P.S., Foltz, D.R., Desai, A.B., Shah, J. V., and Cleveland, D.W. (2007a). Centromere Identity Maintained by Nucleosomes Assembled with Histone H3 Containing the CENP-A Targeting Domain. Mol. Cell 25, 309-322.

Black, B.E., Brock, M.A., Bédard, S., Woods, V.L., and Cleveland, D.W. (2007b). An epigenetic mark generated by the incorporation of CENP-A into centromeric nucleosomes. Proc. Natl. Acad. Sci. U. S. A. 104, 5008-5013.

Blower, M.D., and Karpen, G.H. (2001). The role of Drosophila CID in kinetochore formation, cell-cycle progression and heterochromatin interactions. Nat. Cell Biol. 3, 730-739.

Blower, M.D., Sullivan, B.A., and Karpen, G.H. (2002). Conserved Organization of Centromeric Chromatin in Flies and Humans. Dev. Cell 2, 319-330.

Bodor, D.L., Rodríguez, M.G., Moreno, N., and Jansen, L.E.T. (2012). Analysis of Protein Turnover by Quantitative SNAP-Based Pulse-Chase Imaging. Curr. Protoc. Cell Biol. Chapter 8, Unit8.8.

Bodor, D.L., Valente, L.P., Mata, J.F., Black, B.E., and Jansen, L.E.T. (2013). Assembly in G1 phase and longterm stability are unique intrinsic features of CENP-A nucleosomes. Mol. Biol. Cell 24, 923-932.

Bodor, D.L., Mata, J.F., Sergeev, M., David, A.F., Salimian, K.J., Panchenko, T., Cleveland, D.W., Black, B.E., Shah, J. V., and Jansen, L.E.T.T. (2014). The quantitative architecture of centromeric chromatin. Elife 3, 126.

Brown, W.R.A., and $\mathrm{Xu}, \mathrm{Z}$. (2009). The "kinetochore maintenance loop"-The mark of regulation? BioEssays 31, 228-236.

Buchwitz, B.J., Ahmad, K., Moore, L.L., Roth, M.B., and Henikoff, S. (1999). Cell division: A histone-H3-like 
protein in C. elegans. Nature 401, 547-548.

Carroll, C.W., Silva, M.C.C.C., Godek, K.M., Jansen, L.E.T.T., and Straight, A.F. (2009). Centromere assembly requires the direct recognition of CENP-A nucleosomes by CENP-N. Nat Cell Biol 11, 896-902.

Carroll, C.W., Milks, K.J., and Straight, A.F. (2010). Dual recognition of CENP-A nucleosomes is required for centromere assembly. J. Cell Biol. 189, 1143-1155.

Cheeseman, I.M., and Desai, A. (2008). Molecular architecture of the kinetochore-microtubule interface. Nat. Rev. Mol. Cell Biol. 9, 33-46.

Cheeseman, I.M., Niessen, S., Anderson, S., Hyndman, F., Yates, J.R., Oegema, K., and Desai, A. (2004). A conserved protein network controls assembly of the outer kinetochore and its ability to sustain tension. Genes Dev. 18, 2255-2268.

Cheeseman, I.M., Chappie, J.S., Wilson-Kubalek, E.M., and Desai, A. (2006). The conserved KMN network constitutes the core microtubule-binding site of the kinetochore. Cell 127, 983-997.

Chmátal, L., Gabriel, S.I.I.I., Mitsainas, G.P.P.P., Martínez-Vargas, J., Ventura, J., Searle, J.B.B.B., Schultz, R.M.M.M., and Lampson, M.A.A.A. (2014). Centromere Strength Provides the Cell Biological Basis for Meiotic Drive and Karyotype Evolution in Mice. Curr. Biol. 24, 2295-2300.

Coffman, V.C., Wu, P., Parthun, M.R., and Wu, J.-Q. (2011). CENP-A exceeds microtubule attachment sites in centromere clusters of both budding and fission yeast. J. Cell Biol. 195, 563-572.

Collins, K.A., Furuyama, S., and Biggins, S. (2004). Proteolysis Contributes to the Exclusive Centromere Localization of the Yeast Cse4/CENP-A Histone H3 Variant.

Csink, A.K., and Henikoff, S. (1998). Something from nothing: the evolution and utility of satellite repeats. Trends Genet. 14, 200-204.

Dambacher, S., Deng, W., Hahn, M., Sadic, D., Fröhlich, J., Nuber, A., Hoischen, C., Diekmann, S., Leonhardt, H., and Schotta, G. (2012). CENP-C facilitates the recruitment of M18BP1 to centromeric chromatin. Nucleus 3, 101-110.

Deaton, A.M., Gómez-Rodríguez, M., Mieczkowski, J., Tolstorukov, M.Y., Kundu, S., Sadreyev, R.I., Jansen, L.E., and Kingston, R.E. (2016). Enhancer regions show high histone H3.3 turnover that changes during differentiation. Elife 5, e15316.

DeLuca, J.G., Gall, W.E., Ciferri, C., Cimini, D., Musacchio, A., and Salmon, E.D. (2006). Kinetochore microtubule dynamics and attachment stability are regulated by Hec1. Cell 127, 969-982.

Dodd, I.B., Micheelsen, M.A., Sneppen, K., and Thon, G. (2007). Theoretical Analysis of Epigenetic Cell Memory by Nucleosome Modification. Cell 129, 813-822.

Drinnenberg, I.A., DeYoung, D., Henikoff, S., and Malik, H.S. (2014). Recurrent loss of CenH3 is associated with independent transitions to holocentricity in insects. Elife 3, e03676.

Dunleavy, E.M., Roche, D., Tagami, H., Lacoste, N., Ray-Gallet, D., Nakamura, Y., Daigo, Y., Nakatani, Y., and Almouzni-Pettinotti, G. (2009). HJURP is a cell-cycle-dependent maintenance and deposition factor of CENP-A at centromeres. Cell 137, 485-497.

Dunleavy, E.M., Almouzni, G., and Karpen, G.H. (2011). H3.3 is deposited at centromeres in S phase as a placeholder for newly assembled CENP-A in G(1) phase. Nucleus 2, 146-157.

Dunleavy, E.M., Beier, N.L., Gorgescu, W., Tang, J., Costes, S. V., and Karpen, G.H. (2012). The Cell Cycle Timing of Centromeric Chromatin Assembly in Drosophila Meiosis Is Distinct from Mitosis Yet Requires CAL1 and CENP-C. PLoS Biol 10, e1001460.

Earnshaw, W.C., and Migeon, B.R. (1985). Three related centromere proteins are absent from the inactive centromere of a stable isodicentric chromosome. Chromosoma 92, 290-296.

Earnshaw, W.C., and Rothfield, N. (1985). Identification of a family of human centromere proteins using autoimmune sera from patients with scleroderma. Chromosoma 91, 313-321. 
Fachinetti, D., Diego Folco, H., Nechemia-Arbely, Y., Valente, L.P., Nguyen, K., Wong, A.J., Zhu, Q., Holland, A.J., Desai, A., Jansen, L.E.T., et al. (2013). A two-step mechanism for epigenetic specification of centromere identity and function. Nat. Cell Biol. 15, 1056-1066.

Falk, S.J., Guo, L.Y., Sekulic, N., Smoak, E.M., Mani, T., Logsdon, G.A., Gupta, K., Jansen, L.E.T., Van Duyne, G.D., Vinogradov, S.A., et al. (2015). CENP-C reshapes and stabilizes CENP-A nucleosomes at the centromere. Science (80-. ). 348, 699-703.

Falk, S.J., Lee, J., Sekulic, N., Sennett, M.A., Lee, T.-H., and Black, B.E. (2016). CENP-C directs a structural transition of CENP-A nucleosomes mainly through sliding of DNA gyres. Nat. Struct. Mol. Biol. 23, 204208.

Foltz, D.R., Jansen, L.E.T., Black, B.E., Bailey, A.O., Yates, J.R., and Cleveland, D.W. (2006). The human CENP-A centromeric nucleosome-associated complex. Nat. Cell Biol. 8, 458-469.

Foltz, D.R., Jansen, L.E.T., Bailey, A.O., Yates, J.R., Bassett, E. a., Wood, S., Black, B.E., and Cleveland, D.W. (2009). Centromere-specific assembly of CENP-a nucleosomes is mediated by HJURP. Cell 137, 472-484.

Fujita, Y., Hayashi, T., Kiyomitsu, T., Toyoda, Y., Kokubu, A., Obuse, C., and Yanagida, M. (2007). Priming of centromere for CENP-A recruitment by human hMis18alpha, hMis18beta, and M18BP1. Dev. Cell 12, 1730 .

Furuyama, S., and Biggins, S. (2007). Centromere identity is specified by a single centromeric nucleosome in budding yeast. Proc. Natl. Acad. Sci. U. S. A. 104, 14706-14711.

Gascoigne, K.E., Takeuchi, K., Suzuki, A., Hori, T., Fukagawa, T., and Cheeseman, I.M. (2011). Induced ectopic kinetochore assembly bypasses the requirement for CENP-A nucleosomes. Cell 145, 410-422.

Gassmann, R., Rechtsteiner, A., Yuen, K.W., Muroyama, A., Egelhofer, T., Gaydos, L., Barron, F., Maddox, P., Essex, A., Monen, J., et al. (2012). An inverse relationship to germline transcription defines centromeric chromatin in C. elegans. Nature 484, 534-537.

Gómez-Rodríguez, M., and Jansen, L.E.T. (2013). Basic properties of epigenetic systems: lessons from the centromere. Curr. Opin. Genet. Dev. 23, 219-227.

Guse, A., Carroll, C.W., Moree, B., Fuller, C.J., and Straight, A.F. (2011). In vitro centromere and kinetochore assembly on defined chromatin templates. Nature 477, 354-358.

Haase, J., Mishra, P.K., Stephens, A., Haggerty, R., Quammen, C., Taylor, R.M., Yeh, E., Basrai, M.A., and Bloom, K. (2013). A 3D map of the yeast kinetochore reveals the presence of core and accessory centromere-specific histone. Curr. Biol. 23, 1939-1944.

Hasson, D., Panchenko, T., Salimian, K.J., Salman, M.U., Sekulic, N., Alonso, A., Warburton, P.E., and Black, B.E. (2013). The octamer is the major form of CENP-A nucleosomes at human centromeres. Nat. Struct. Mol. Biol. advance on, 687-695.

Hemmerich, P., Weidtkamp-Peters, S., Hoischen, C., Schmiedeberg, L., Erliandri, I., and Diekmann, S. (2008). Dynamics of inner kinetochore assembly and maintenance in living cells. J. Cell Biol. 180, 11011114.

Henikoff, S., Ahmad, K., Platero, J.S., and Steensel, B. van (2000). Heterochromatic deposition of centromeric histone H3-like proteins. Proc. Natl. Acad. Sci. 97, 716-721.

Heun, P., Erhardt, S., Blower, M.D., Weiss, S., Skora, A.D., and Karpen, G.H. (2006). Mislocalization of the Drosophila centromere-specific histone CID promotes formation of functional ectopic kinetochores. Dev. Cell 10, 303-315.

Hoffmann, S., Dumont, M., Barra, V., Ly, P., Nechemia-Arbely, Y., McMahon, M.A., Hervé, S., Cleveland, D.W., Fachinetti, D., Bade, D., et al. (2016). CENP-A Is Dispensable for Mitotic Centromere Function after Initial Centromere/Kinetochore Assembly. Cell Rep. 17, 2394-2404.

Hori, T., Shang, W.-H.H., Takeuchi, K., and Fukagawa, T. (2013). The CCAN recruits CENP-A to the centromere and forms the structural core for kinetochore assembly. J. Cell Biol. 200, 45-60. 
Howman, E. V., Fowler, K.J., Newson, A.J., Redward, S., MacDonald, A.C., Kalitsis, P., and Choo, K.H.A. (2000). Early disruption of centromeric chromatin organization in centromere protein A (Cenpa) null mice. Proc. Natl. Acad. Sci. 97, 1148-1153.

Hudson, D.F., Fowler, K.J., Earle, E., Saffery, R., Kalitsis, P., Trowell, H., Hill, J., Wreford, N.G., Kretser, D.M. de, Cancilla, M.R., et al. (1998). Centromere Protein B Null Mice are Mitotically and Meiotically Normal but Have Lower Body and Testis Weights. J. Cell Biol. 141, 309-319.

Izuta, H., Ikeno, M., Suzuki, N., Tomonaga, T., Nozaki, N., Obuse, C., Kisu, Y., Goshima, N., Nomura, F., Nomura, N., et al. (2006). Comprehensive analysis of the ICEN (Interphase Centromere Complex) components enriched in the CENP-A chromatin of human cells. Genes to Cells 11, 673-684.

Jansen, L.E.T., Black, B.E., Foltz, D.R., and Cleveland, D.W. (2007). Propagation of centromeric chromatin requires exit from mitosis. J. Cell Biol. 176, 795-805.

Joglekar, A.P., Bouck, D.C., Molk, J.N., Bloom, K.S., and Salmon, E.D. (2006). Molecular architecture of a kinetochore-microtubule attachment site. Nat. Cell Biol. 8, 581-585.

Joglekar, A.P., Bouck, D., Finley, K., Liu, X., Wan, Y., Berman, J., He, X., Salmon, E.D., and Bloom, K.S. (2008). Molecular architecture of the kinetochore-microtubule attachment site is conserved between point and regional centromeres. J. Cell Biol. 181, 587-594.

Johnston, K., Joglekar, A., Hori, T., Suzuki, A., Fukagawa, T., and Salmon, E.D.D. (2010). Vertebrate kinetochore protein architecture: protein copy number. J. Cell Biol. 189, 937-943.

Kanesaki, Y., Imamura, S., Matsuzaki, M., and Tanaka, K. (2015). Identification of centromere regions in chromosomes of a unicellular red alga, Cyanidioschyzon merolae. FEBS Lett. 589, 1219-1224.

Kato, H., Jiang, J., Zhou, B.-R., Rozendaal, M., Feng, H., Ghirlando, R., Xiao, T.S., Straight, A.F., and Bai, Y. (2013). A Conserved Mechanism for Centromeric Nucleosome Recognition by Centromere Protein CENPC. Science (80-.) ). 340, 1110-1113.

Keppler, A., Gendreizig, S., Gronemeyer, T., Pick, H., Vogel, H., and Johnsson, K. (2003). A general method for the covalent labeling of fusion proteins with small molecules in vivo. Nat. Biotechnol. 21, 86-89.

Lacoste, N., Woolfe, A., Tachiwana, H., Garea, A.V., Barth, T., Cantaloube, S., Kurumizaka, H., Imhof, A., and Almouzni, G. (2014). Mislocalization of the Centromeric Histone Variant CenH3/CENP-A in Human Cells Depends on the Chaperone DAXX. Mol. Cell 53, 631-644.

Lagana, A.A., Dorn, J.F., De Rop, V.V., Ladouceur, A.-M., Maddox, A.S., and Maddox, P.S. (2010). A small GTPase molecular switch regulates epigenetic centromere maintenance by stabilizing newly incorporated CENP-A. Nat Cell Biol 12, 1186-1193.

Lando, D., Endesfelder, U., Berger, H., Subramanian, L., Dunne, P.D., McColl, J., Klenerman, D., Carr, A.M., Sauer, M., Allshire, R.C., et al. (2012). Quantitative single-molecule microscopy reveals that CENP-ACnp1 deposition occurs during G2 in fission yeast. Open Biol. 2, 120078.

Lawrimore, J., Bloom, K.S., and Salmon, E.D. (2011). Point centromeres contain more than a single centromere-specific Cse4 (CENP-A) nucleosome. J. Cell Biol. 195, 573-582.

Leake, M.C., Chandler, J.H., Wadhams, G.H., Bai, F., Berry, R.M., and Armitage, J.P. (2006). Stoichiometry and turnover in single, functioning membrane protein complexes. Nature 443, 355-358.

Lermontova, I., Schubert, V., Fuchs, J., Klatte, S., Macas, J., and Schubert, I. (2006). Loading of Arabidopsis centromeric histone CENH3 occurs mainly during G2 and requires the presence of the histone fold domain. Plant Cell 18, 2443-2451.

Lidsky, P. V., Sprenger, F., and Lehner, C.F. (2013). Distinct modes of centromere protein dynamics during cell cycle progression in Drosophila S2R+ cells. J. Cell Sci. 126, 4782-4793.

Liu, C., and Mao, Y. (2016). Diaphanous formin mDia2 regulates CENP-A levels at centromeres. J. Cell Biol. 213, 415-424.

Liu, S.-T., Rattner, J.B., Jablonski, S.A., and Yen, T.J. (2006). Mapping the assembly pathways that specify 
formation of the trilaminar kinetochore plates in human cells. J. Cell Biol. 175, 41-53.

Malik, H.S., and Henikoff, S. (2003). Phylogenomics of the nucleosome. Nat. Struct. Mol. Biol. 10, 882-891.

Maruyama, S., Kuroiwa, H., Miyagishima, S., Tanaka, K., and Kuroiwa, T. (2007). Centromere dynamics in the primitive red alga Cyanidioschyzon merolae. Plant J. 49, 1122-1129.

McEwen, B.F., Chan, G.K.T.T., Zubrowski, B., Savoian, M.S., Sauer, M.T., and Yen, T.J. (2001). CENP-E Is Essential for Reliable Bioriented Spindle Attachment, but Chromosome Alignment Can Be Achieved via Redundant Mechanisms in Mammalian Cells. Mol. Biol. Cell 12, 2776-2789.

McKinley, K.L.L.L., and Cheeseman, I.M.M.M. (2014). Polo-like Kinase 1 Licenses CENP-A Deposition at Centromeres. Cell 158, 397-411.

Mellone, B.G., Grive, K.J., Shteyn, V., Bowers, S.R., Oderberg, I., and Karpen, G.H. (2011). Assembly of Drosophila centromeric chromatin proteins during mitosis. PLoS Genet. 7, e1002068.

Mendiburo, M.J., Padeken, J., Fülöp, S., Schepers, A., and Heun, P. (2011). Drosophila CENH3 Is Sufficient for Centromere Formation. Science (80-. ). 334, 686-690.

Milks, K.J., Moree, B., and Straight, A.F. (2009). Dissection of CENP-C-directed centromere and kinetochore assembly. Mol. Biol. Cell 20, 4246-4255.

Monen, J., Maddox, P.S., Hyndman, F., Oegema, K., and Desai, A. (2005). Differential role of CENP-A in the segregation of holocentric C. elegans chromosomes during meiosis and mitosis. Nat. Cell Biol. 7, 12481255.

Moree, B., Meyer, C.B., Fuller, C.J., and Straight, A.F. (2011). CENP-C recruits M18BP1 to centromeres to promote CENP-A chromatin assembly. J. Cell Biol. 194, 855-871.

Müller, S., Montes de Oca, R., Lacoste, N., Dingli, F., Loew, D., Almouzni, G., Montes de Oca, R., Lacoste, N., Dingli, F., Loew, D., et al. (2014). Phosphorylation and DNA Binding of HJURP Determine Its Centromeric Recruitment and Function in CenH3(CENP-A) Loading. Cell Rep. 8, 190-203.

Nardi, I.K.K., Zasadzińska, E., Stellfox, M.E.E., Knippler, C.M.M., and Foltz, D.R.R. (2016). Licensing of Centromeric Chromatin Assembly through the Mis18 $\alpha$-Mis18 $\beta$ Heterotetramer. Mol. Cell 61, 774-787.

Niikura, Y., Kitagawa, R., and Kitagawa, K. (2016). CENP-A Ubiquitylation Is Inherited through Dimerization between Cell Divisions. Cell Rep. 15, 61-76.

Okada, M., Cheeseman, I.M., Hori, T., Okawa, K., McLeod, I.X., Yates, J.R. 3rd, Desai, A., and Fukagawa, T. (2006). The CENP-H-I complex is required for the efficient incorporation of newly synthesized CENP-A into centromeres. Nat. Cell Biol. 8, 446-457.

Olszak, A.M., van Essen, D., Pereira, A.J., Diehl, S., Manke, T., Maiato, H., Saccani, S., and Heun, P. (2011). Heterochromatin boundaries are hotspots for de novo kinetochore formation. Nat. Cell Biol. 13, 799-808.

Palmer, D.K., O’Day, K., Wener, M.H., Andrews, B.S., and Margolis, R.L. (1987). A 17-kD centromere protein (CENP-A) copurifies with nucleosome core particles and with histones. J. Cell Biol. 104, 805-815.

Palmer, D.K., O’Day, K., and Margolis, R.L. (1990). The centromere specific histone CENP-A is selectively retained in discrete foci in mammalian sperm nuclei. Chromosoma 100, 32-36.

Pearson, C.G., Maddox, P.S., Salmon, E.D., and Bloom, K. (2001). Budding Yeast Chromosome Structure and Dynamics during Mitosis. J. Cell Biol. 152, 1255-1266.

Pearson, C.G., Yeh, E., Gardner, M., Odde, D., Salmon, E.D., and Bloom, K. (2004). Stable KinetochoreMicrotubule Attachment Constrains Centromere Positioning in Metaphase. Curr. Biol. 14, 1962-1967.

Perpelescu, M., Nozaki, N., Obuse, C., Yang, H., and Yoda, K. (2009). Active establishment of centromeric CENP-A chromatin by RSF complex. J. Cell Biol. 185, 397-407.

Pluta, A.F., Saitoh, N., Goldberg, I., and Earnshaw, W.C. (1992). Identification of a subdomain of CENP-B that is necessary and sufficient for localization to the human centromere. J. Cell Biol. 116, 1081-1093. 
Prendergast, L., van Vuuren, C., Kaczmarczyk, A., Doering, V., Hellwig, D., Quinn, N., Hoischen, C., Diekmann, S., and Sullivan, K.F. (2011). Premitotic assembly of human CENPs -T and -W switches centromeric chromatin to a mitotic state. PLoS Biol. 9, e1001082.

Raychaudhuri, N., Dubruille, R., Orsi, G. a., Bagheri, H.C., Loppin, B., and Lehner, C.F. (2012). Transgenerational Propagation and Quantitative Maintenance of Paternal Centromeres Depends on Cid/Cenp-A Presence in Drosophila Sperm. PLoS Biol. 10, e1001434.

Ray-Gallet, D., Woolfe, A., Vassias, I., Pellentz, C., Lacoste, N., Puri, A., Schultz, D.C.C.C., Pchelintsev, N.A. a. a., Adams, P.D.D.D., Jansen, L.E.T.E.T.T., et al. (2011). Dynamics of histone H3 deposition in vivo reveal a nucleosome gap-filling mechanism for H3.3 to maintain chromatin integrity. Mol. Cell 44, 928-941.

Régnier, V., Vagnarelli, P., Fukagawa, T., Zerjal, T., Burns, E., Trouche, D., Earnshaw, W., and Brown, W. (2005). CENP-A is required for accurate chromosome segregation and sustained kinetochore association of BubR1. Mol. Cell. Biol. 25, 3967-3981.

Ribeiro, S.A., Vagnarelli, P., Dong, Y., Hori, T., McEwen, B.F., Fukagawa, T., Flors, C., and Earnshaw, W.C. (2010). A super-resolution map of the vertebrate kinetochore. Proc. Natl. Acad. Sci. U. S. A. 107, 1048410489.

Ross, J.E., Woodlief, K.S., and Sullivan, B.A. (2016). Inheritance of the CENP-A chromatin domain is spatially and temporally constrained at human centromeres. Epigenetics Chromatin 9, 20.

Sagolla, M.J., Uzawa, S., and Cande, W.Z. (2003). Individual microtubule dynamics contribute to the function of mitotic and cytoplasmic arrays in fission yeast. J. Cell Sci. 116.

Schittenhelm, R.B., Althoff, F., Heidmann, S., and Lehner, C.F. (2010). Detrimental incorporation of excess Cenp-A/Cid and Cenp-C into Drosophila centromeres is prevented by limiting amounts of the bridging factor Cal1. J. Cell Sci. 123, 3768-3779.

Schuh, M., Lehner, C.F., and Heidmann, S. (2007). Incorporation of Drosophila CID/CENP-A and CENP-C into Centromeres during Early Embryonic Anaphase. Curr. Biol. 17, 237-243.

Shelby, R.D., Vafa, O., and Sullivan, K.F. (1997). Assembly of CENP-A into Centromeric Chromatin Requires a Cooperative Array of Nucleosomal DNA Contact Sites. J. Cell Biol. 136, 501-513.

Shelby, R.D., Monier, K., and Sullivan, K.F. (2000). Chromatin Assembly at Kinetochores Is Uncoupled from DNA Replication. J. Cell Biol. 151, 1113-1118.

Shivaraju, M., Unruh, J.R.R., Slaughter, B.D.D., Mattingly, M., Berman, J., Gerton, J.L.L.J.L.J.L.L., Alber, F., Dokudovskaya, S., Veenhoff, L.M., Zhang, W., et al. (2012). Cell-Cycle-Coupled Structural Oscillation of Centromeric Nucleosomes in Yeast. Cell 150, 304-316.

Shono, N., Ohzeki, J.-I., Otake, K., Martins, N.M.C., Nagase, T., Kimura, H., Larionov, V., Earnshaw, W.C., and Masumoto, H. (2015). CENP-C and CENP-I are key connecting factors for kinetochore and CENP-A assembly. J. Cell Sci. jcs.180786-.

Silva, M.C.C., Bodor, D.L., Stellfox, M.E., Martins, N.M.C., Hochegger, H., Foltz, D.R., and Jansen, L.E.T. (2012). Cdk Activity Couples Epigenetic Centromere Inheritance to Cell Cycle Progression. Dev. Cell 22, $52-63$.

Smoak, E.M., Stein, P., Schultz, R.M., Lampson, M.A., and Black, B.E. (2016). Long-Term Retention of CENPA Nucleosomes in Mammalian Oocytes Underpins Transgenerational Inheritance of Centromere Identity. Curr. Biol. 26, 1110-1116.

Stankovic, A., Guo, L.Y., Mata, J.F., Bodor, D.L., Cao, X.-Y., Bailey, A.O., Shabanowitz, Jeffrey, Hunt, D.F., Garcia, B.A., Black, B.E., and Jansen, L.E.T. (2017). A dual inhibitory mechanism sufficient to maintain cell cycle restricted CENP-A assembly. Mol. Cell in press.

Steiner, F.A., and Henikoff, S. (2014). Holocentromeres are dispersed point centromeres localized at transcription factor hotspots. Elife 2014.

Stellfox, M.E., Nardi, I.K., Knippler, C.M., and Foltz, D.R. (2016). Differential Binding Partners of the Mis18 $\alpha / \beta$ YIPPEE Domains Regulate Mis18 Complex Recruitment to Centromeres. Cell Rep. 1-9. 
Stoler, S., Keith, K.C., Curnick, K.E., and Fitzgerald-Hayes, M. (1995). A mutation in CSE4, an essential gene encoding a novel chromatin-associated protein in yeast, causes chromosome nondisjunction and cell cycle arrest at mitosis. Genes Dev. 9, 573-586.

Sullivan, K.F., Hechenberger, M., and Masri, K. (1994). Human CENP-A contains a histone H3 related histone fold domain that is required for targeting to the centromere. J. Cell Biol. 127, 581-592.

Talbert, P.B., and Henikoff, S. (2013). Phylogeny as the basis for naming histones. Trends Genet. 29, 499500.

Talbert, P.B., Masuelli, R., Tyagi, A.P., Comai, L., and Henikoff, S. (2002). Centromeric Localization and Adaptive Evolution of an Arabidopsis Histone H3 Variant. Plant Cell Online 14, 1053-1066.

Talbert, P.B., Ahmad, K., Almouzni, G., Ausió, J., Berger, F., Bhalla, P.L., Bonner, W.M., Cande, W.Z., Chadwick, B.P., Chan, S.W.L., et al. (2012). A unified phylogeny-based nomenclature for histone variants. Epigenetics Chromatin 5, 7.

Tyler-Smith, C., Gimelli, G., Giglio, S., Floridia, G., Pandya, A., Terzoli, G., Warburton, P.E., Earnshaw, W.C., and Zuffardi, O. (1999). Transmission of a Fully Functional Human Neocentromere through Three Generations. Am. J. Hum. Genet. 64, 1440-1444.

Voullaire, L.E., Slater, H.R., Petrovic, V., and Choo, K.H. (1993). A functional marker centromere with no detectable alpha-satellite, satellite III, or CENP-B protein: activation of a latent centromere? Am. J. Hum. Genet. 52, 1153-1163.

Wang, J., Liu, X., Dou, Z., Chen, L., Jiang, H., Fu, C., Fu, G., Liu, D., Zhang, J., Zhu, T., et al. (2014). Mitotic Regulator Mis18 Interacts with and Specifies the Centromeric Assembly of Molecular Chaperone Holliday Junction Recognition Protein (HJURP). J. Biol. Chem. 289, 8326-8336.

Westhorpe, F.G., Fuller, C.J., and Straight, A.F. (2015). A cell-free CENP-A assembly system defines the chromatin requirements for centromere maintenance. J. Cell Biol. jcb.201503132-.

Wisniewski, J., Hajj, B., Chen, J., Mizuguchi, G., Xiao, H., Wei, D., Dahan, M., and Wu, C. (2014). Imaging the fate of histone $\mathrm{Cse} 4$ reveals de novo replacement in $\mathrm{S}$ phase and subsequent stable residence at centromeres. Elife 3, e02203.

Zinkowski, R.P., Meyne, J., and Brinkley, B.R. (1991). The centromere-kinetochore complex: a repeat subunit model. J. Cell Biol. 113, 1091-1110. 
A
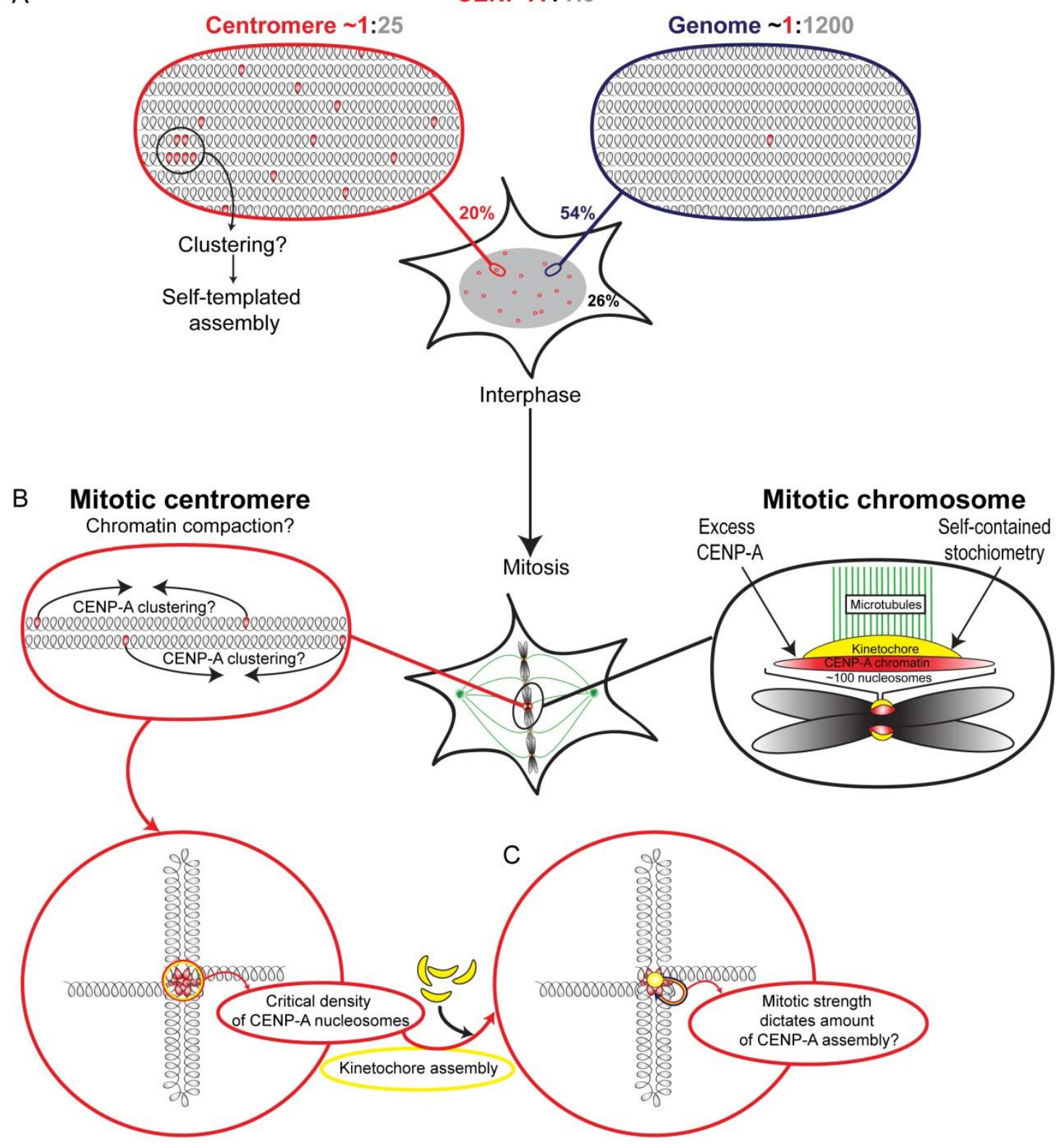

Figure 1. An integrated view of human centromere architecture. (A) Interphase distribution of CENP-A relative to histone $\mathrm{H} 3$ at an average human centromere (left) and whole genome level (right) adapted from (Bodor et al., 2014). (B) Organization of mitotic chromosome in which individual centromeres contain 100 CENP-A nucleosomes, which is in excess of what is required to nucleate the kinetochore of a fixed size (right). Compaction of centromeric chromatin during mitosis possibly leads to clustering of CENP-A nucleosomes, which may reach a critical density of CENP-A nucleosomes for efficient kinetochore assembly (left and bottom). (C) Normalization of CENP-A levels could be initiated during mitosis through signals dictated by microtubule pulling forces. 


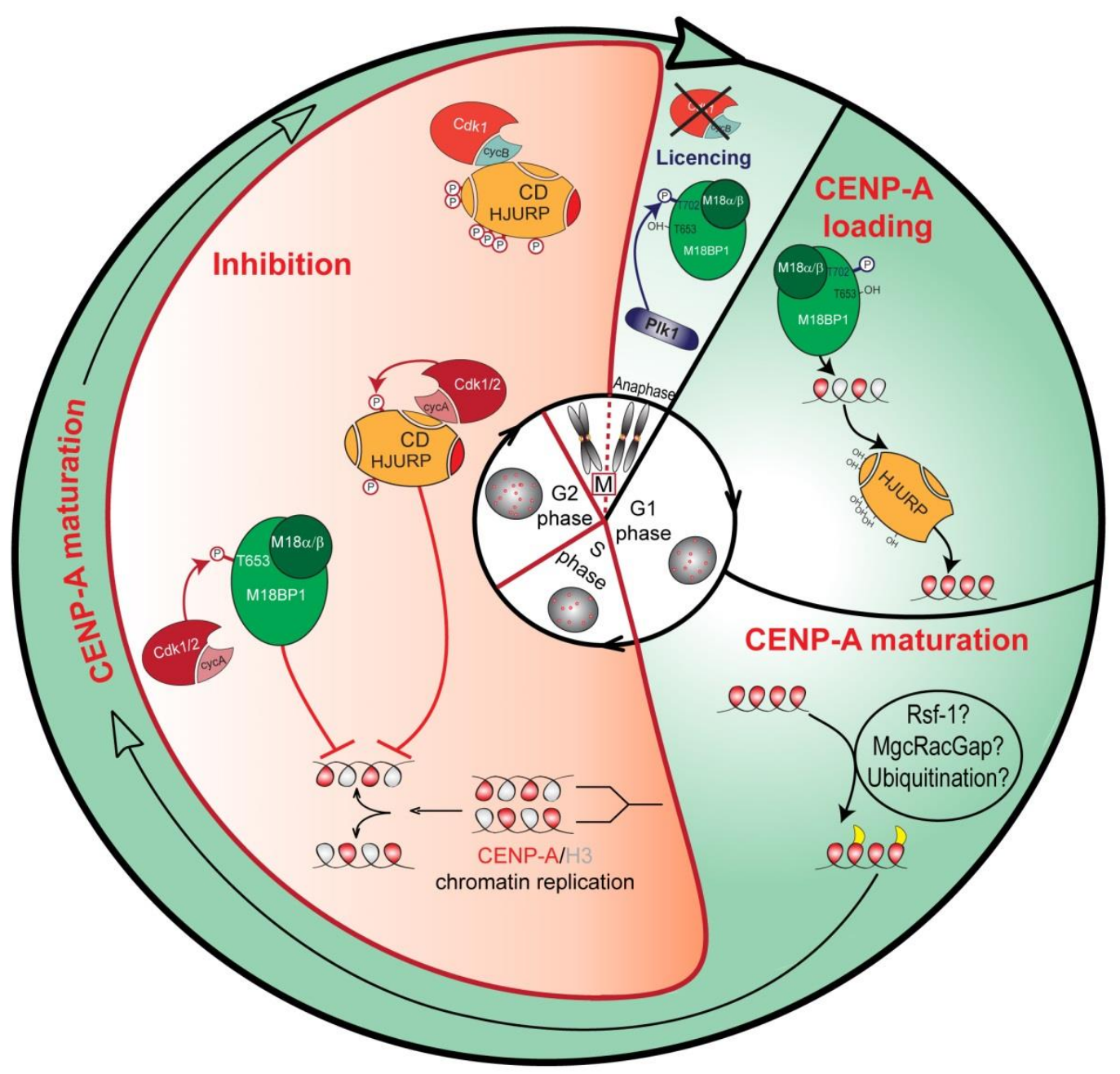

Figure 2. Overview of mechanisms ensuring cell-cycle coupled CENP-A assembly. CENP-A deposition is restricted to early G1 phase by the Cdk1/2 based phosphorylation of two key loading factors, M18BP1 and HJURP. During mitosis, positive regulation takes place in a form of licencing phosphorylation of M18BP1 by Plk1. Upon mitotic exit, negative regulation is alleviated and CENP-A assembly initiates. An additional step of "maturation" may be necessary in order to stabilize newly-loaded pool of CENP-A and to normalize CENP-A levels. 


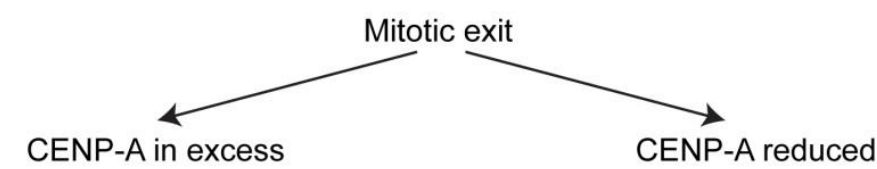

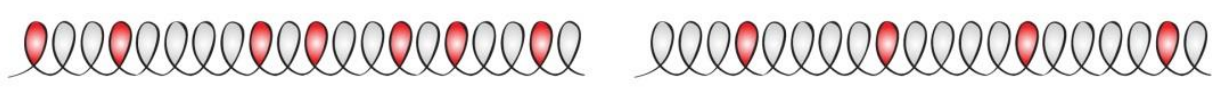

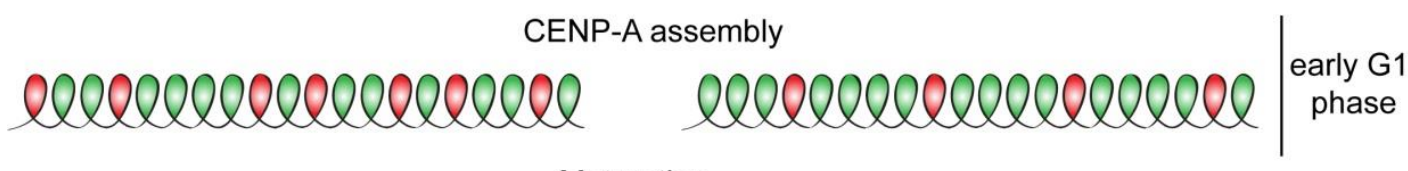

Maturation

(Eviction+Stabilization)

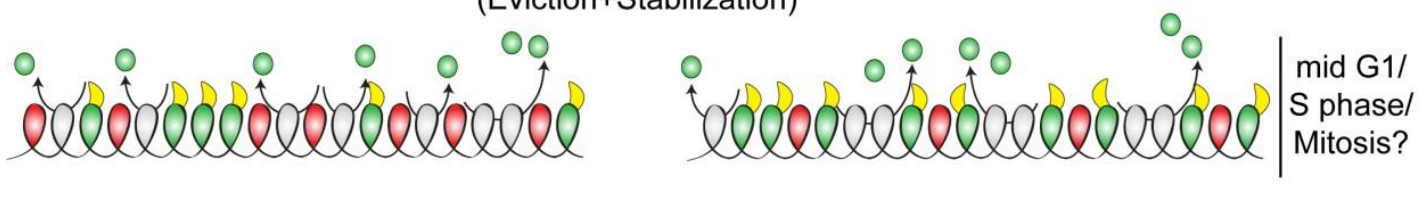

Propagation

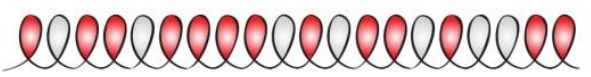

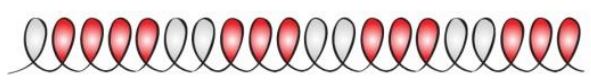

$\begin{array}{ll}\text { Q Parental CENP-A nucleosomes } & \text { C } \mathrm{H} 3 \text { containing nucleosomes } \\ \text { \& Newly deposited CENP-A nucleosomes } & D \text { CENP-A stabilization mark(s) }\end{array}$

Figure 3. A model for normalization of CENP-A levels across mitotic divisions. Stochastic redistribution of CENP-A during $S$ phase may give rise to daughter centromeres having an unequal amount of parental nucleosomes upon mitotic exit. To accommodate for this, an excessive amount of nascent CENP-A is deposited to the centromere in early G1 phase, followed by selective stabilization of a portion of newly loaded CENP-A molecules. This would occur in an inverse proportion to the number of parental nucleosomes: the greater the number of parental nucleosomes is, the smaller the pool of new CENP-A is marked for stability, the remainder of which will be evicted. The combination of these two processes (stabilization and eviction) could encompass previously proposed "maturation" step of centromeric chromatin. 